\title{
Association of high-sensitivity C-reactive protein and uric acid with the metabolic syndrome components
}

\author{
Santosh Kumar Sah ${ }^{1}$, Saroj Khatiwada ${ }^{2 *}$, Sunil Pandey ${ }^{3}$, Rajendra KC ${ }^{2}$, Binod Kumar Lal Das ${ }^{3}$, Nirmal Baral ${ }^{3}$ \\ and Madhab Lamsal ${ }^{3}$
}

\begin{abstract}
Metabolic syndrome (MetS) has been found to be associated with inflammatory molecules. This study was conducted among 125 MetS patients at B P Koirala Institute of Health Sciences, Dharan, Nepal to find an association of highsensitivity C-reactive protein (hs-CRP) and serum uric acid with MetS components. Anthropometric measurements, blood pressure, medical history and blood samples were taken. Estimation of hs-CRP, serum uric acid, blood glucose, triglyceride and high density lipoprotein (HDL) cholesterol was done. hs-CRP had positive correlation with blood glucose $(r=0.2, p=0.026)$ and negative with $\mathrm{HDL}$ cholesterol $(r=-0.361, p<0.001)$. Serum uric acid had positive correlation with waist circumference $(r=0.178, p=0.047)$. Patients with elevated hs-CRP and uric acid had higher waist circumference $(p=0.03)$, diastolic BP $(p=0.002)$ and lower HDL cholesterol $(p=0.004)$ than others. Elevated hs-CRP and high uric acid were individually associated with higher odds for low HDL cholesterol (7.992; 1.785-35.774, $p=0.002)$ and hyperglycemia $(2.471 ; 1.111-5.495, p=0.029)$ respectively. Combined rise of hs-CRP and uric acid was associated with severity of MetS $(p<0.001)$ and higher odds for hyperglycemia $(8.036 ; 2.178-29.647, p=0.001)$ as compared to individual rise of hs-CRP or uric acid. The present study demonstrates that hs-CRP and serum uric acid are associated with MetS components, and the combined rise of hs-CRP and uric acid is associated with the increase in severity of MetS.
\end{abstract}

Keywords: High-sensitivity C-reactive protein, Metabolic syndrome, Nepal, Uric acid

\section{Background}

Metabolic syndrome (MetS) is the clustering of several cardiovascular risk factors leading to increased risk of developing cardiovascular disease (CVD) and dying (Paoletti et al. 2006). MetS is a major and escalating public health and clinical challenge worldwide and is rising throughout the globe including developing countries like Nepal (Kaur 2014; O’Neill and O'Driscoll 2015; Sharma et al. 2011). Thus it is important to study the factors responsible for rapid rise of MetS and investigate markers that can predict risk for MetS early and the risk for future adverse events. Since, MetS is a state of chronic

\footnotetext{
*Correspondence: khatiwadasaroj22@gmail.com

${ }^{2}$ Department of Biochemistry, Modern Technical College, Sanepa,

Lalitpur, Nepal

Full list of author information is available at the end of the article
}

low grade inflammation as a consequence of complex interplay between genetic and environmental factors, inflammatory molecules seem to mediate the MetS components (Kaur 2014; Ma et al. 2012). Measurements of the circulating levels of the inflammatory molecules that accompany this syndrome might provide therapeutic approaches to modulate the inflammatory responses and thereby alter disease progression (Ma et al. 2012).

High-sensitivity C-reactive protein (hs-CRP) has been found to be associated with MetS. Hs-CRP is highly predictive of subsequent risk of cardiovascular events and diabetes mellitus in apparently healthy men and women (den Engelsen et al. 2012). Though, hs-CRP may serve as early marker for CVD and MetS, there is less evidence about relationship between hs-CRP level and the severity of MetS (as quantified by the increasing concurrence of individual MetS components; 3, 4 or 5), and there are evidences that

\section{贷 Springer}

(c) 2016 Sah et al. This article is distributed under the terms of the Creative Commons Attribution 4.0 International License (http:// creativecommons.org/licenses/by/4.0/), which permits unrestricted use, distribution, and reproduction in any medium, provided you give appropriate credit to the original author(s) and the source, provide a link to the Creative Commons license, and indicate if changes were made. 
addition of hs-CRP to the present definition of the MetS may help identify patients at high risk for future diabetes and CVD (Devaraj et al. 2009). Elevated serum uric acid level has been seen in MetS, and there appears to be link between MetS and serum uric acid (Serpa Neto et al. 2011). Hyperuricemia predicts the development of hypertension, obesity, and type 2 diabetes mellitus. Thus, uric acid may not only acts as surrogate marker of MetS, but also have a pathogenic role in the development of MetS, and therapies that lower uric acid may improve certain components of MetS (Billiet et al. 2014). Though an association between hyperuricemia and hs-CRP has been observed, the combined effect of hs-CRP and uric acid increase on MetS components is inadequately defined (Kawamoto et al. 2013). Thus it seems important to assess combined effects due to hs-CRP and uric acid rise on MetS parameters and to find if combined rise of hs-CRP and uric acid may have more severe effects on MetS than their individual rise.

Ethnicity has been suggested as a major factor in determining expression level of various metabolic markers and their association with CVD, type 2 diabetes and MetS (Abu-Farha et al. 2014). Studies investigating hs-CRP and uric acid in MetS are lacking in Nepalese population, and the clinical importance of measuring such markers has not been studied in Nepalese population. In the light of this gap in evidence from our settings and the undefined relationships between combined effects of h-CRP and uric acid rise on MetS components, we conducted a study among Nepalese MetS patients to explore the relationship between hs-CRP, serum uric acid and MetS components. The study also aims to evaluate the effect of the combined rise of hs-CRP and uric acid on MetS components.

\section{Methods}

It was a cross-sectional study involving 125 MetS patients recruited at Department of Biochemistry of B P Koirala Institute of Health Sciences, Nepal. The aim was to find an association between hs-CRP, serum uric acid and MetS components, and to determine whether combined increase of hs-CRP and serum uric acid is associated with MetS components. The study patients were recruited from the B P Koirala Institute of Health Sciences conveniently using the study inclusion criteria. Following informed consent, blood pressure (BP) were measured using standard methods and $5 \mathrm{ml}$ of fasting blood samples were collected from the patients whose waist circumference were $\geq 90 \mathrm{~cm}$ in men and $\geq 80 \mathrm{~cm}$ in women. Only patients fulfilling International Diabetes Federation (IDF) criteria for MetS were enrolled in the study. According to this criteria; for a person to be defined as having the MetS they must have; central obesity (defined as waist circumference with ethnicity specific values, for South Asians: waist circumference $\geq 90$
$\mathrm{Cm}$ for males and $\geq 80 \mathrm{Cm}$ for females), plus any two of the following four factors: triglycerides $\geq 150 \mathrm{mg} / \mathrm{dL}$ or on treatment for lowering this lipid, high density lipoprotein (HDL) cholesterol $<40 \mathrm{mg} / \mathrm{dL}$ in men or $<50 \mathrm{mg} / \mathrm{dL}$ in women or on treatment for HDL cholesterol, systolic $\mathrm{BP} \geq 130 \mathrm{~mm} \mathrm{Hg}$ or diastolic $\mathrm{BP} \geq 85 \mathrm{~mm} \mathrm{Hg}$ or on treatment for hypertension, fasting blood glucose $\geq 100 \mathrm{mg}$ / dL or on treatment for type 2 diabetes (Kaur 2014). Raised BP or hypertension, raised glucose or hyperglycemia, hypertriglyceridemia and low HDL was considered if the subject's systolic BP $\geq 130 \mathrm{~mm} \mathrm{Hg}$ or diastolic BP $\geq 85 \mathrm{~mm} \mathrm{Hg}$, fasting blood glucose $\geq 100 \mathrm{mg} / \mathrm{dL}$, triglycerides $\geq 150 \mathrm{mg} / \mathrm{dL}$ and HDL cholesterol $<40 \mathrm{mg} / \mathrm{dL}$ in men or $<50 \mathrm{mg} / \mathrm{dL}$ in women respectively (Kaur 2014). Exclusion criteria of the participants include: presence of acute infections and chronic inflammatory diseases, gout patients. After defining MetS, each patient demographic characteristics (age, sex), height, weight, medical history of diabetes mellitus and hypertension were noted. The study protocol was approved by the institute review board of B P Koirala Institute of Health Sciences.

Serums from overnight fasting blood samples were stored at $-20{ }^{\circ} \mathrm{C}$ until analysis. Blood glucose was estimated using enzymatic method. Serum triglyceride was measured by enzymatic method (kits from AGAPPE diagnostics). High density lipoprotein (HDL) cholesterol was estimated by homogeneous, direct method using kit from Gesan by Biolyzer 100, and hs-CRP was measured by enzyme immunoassay using kit from diagnostics biochem canada (DBC) and the reading was taken using LabLife ER 2007 plate reader. Uric acid was measured by uricase peroxidase method. We dichotomized hs-CRP (hs-CRP $<1 \mathrm{mg} / \mathrm{L}$ as non-elevated hs-CRP and low risk group, and hs-CRP $\geq 1 \mathrm{mg} / \mathrm{L}$ as elevated hs-CRP and high risk group) and serum uric acid (serum uric acid $<6 \mathrm{mg} /$ $\mathrm{dL}$ as normal uric acid group and serum uric acid $\geq 6 \mathrm{mg}$ / $\mathrm{dL}$ as hyperuricemia group) and analyzed MetS components in each group. We used hs-CRP $<1$ or $\geq 1 \mathrm{mg} / \mathrm{L}$ and serum uric acid $<6$ or $\geq 6 \mathrm{mg} / \mathrm{dL}$ as a cutoff. Usually, hs$\mathrm{CRP} \geq 1 \mathrm{mg} / \mathrm{L}$, indicates intermediate or high cardiovascular risk, whereas, hs-CRP $<1 \mathrm{mg} / \mathrm{L}$ is considered a low cardiovascular risk (den Engelsen et al. 2012). We took uric acid $\geq 6 \mathrm{mg} / \mathrm{dL}$ as high uric acid/hyperuricemia since exact cutoff of serum uric acid for hyperuricemia in Nepalese population has not been established, and uric acid level even at upper normal range could bring risk for having MetS components, and some define hyperuricemia as uric acid $>6 \mathrm{mg} / \mathrm{dL}$ (women) and $>6.8 \mathrm{mg} / \mathrm{dL}$ (men) (Billiet et al. 2014; Serpa Neto et al. 2011). Similarly, we compared MetS components among 4 groups made by considering both hs-CRP and serum uric acid; group one with hs-CRP $<1 \mathrm{mg} / \mathrm{L}$ and normal uric acid, group two with hs-CRP $<1 \mathrm{mg} / \mathrm{L}$ and hyperuricemia, group three 
with hs-CRP $\geq 1 \mathrm{mg} / \mathrm{L}$ and normal uric acid and group four with hs-CRP $\geq 1 \mathrm{mg} / \mathrm{L}$ and hyperuricemia.

The data were analyzed using SPSS version 20 . The continuous variables were expressed as mean \pm SD for variables showing normal distribution, and as median with interquartile rage for variables showing non-normal distribution. Categorical variables are expressed as number (percentage). Correlations between hs-CRP and MetS components were calculated using Spearman rank correlation analysis, and between serum uric acid level and MetS components using Pearson's correlation analysis at $95 \%$ confidence interval. Correlation between hsCRP and uric acid level was measured using Spearman rank correlation analysis at $95 \%$ confidence interval. Independent $\mathrm{t}$ test, one way ANOVA, Man Whitney test and Kruskal-Wallis test were applied at $95 \%$ confidence interval to test for the significance. The odds ratio with $95 \%$ CI was estimated to find risk for having hypertension, hyperglycemia, hypertriglyceridemia and low HDL in patients with elevated hs-CRP, hyperuricemia or both as compared to those with low hs-CRP, uric acid or both respectively. A $p$ value less than 0.05 was considered as statistically significant at $95 \%$ confidence interval.

\section{Results}

The mean age of the study population was $47.5 \pm 11.1$ years (age range 22-73 years). Males and females were $44 \%(n=55)$ and $56 \%(n=70)$ respectively. History of diabetes mellitus and hypertension was present in $55.2 \%(\mathrm{n}=69)$ and $76 \%(\mathrm{n}=95)$ respectively. Mean height, weight and BMI of study population were $158.5 \pm 8.2 \mathrm{Cm}, 70.1 \pm 9.6 \mathrm{~kg}$ and $27.9 \pm 3.4 \mathrm{~kg} /$ $\mathrm{m}^{2}$ respectively. The mean level of MetS components; waist circumference, systolic BP, diastolic BP, fasting blood glucose, triglyceride and HDL cholesterol were $103.8 \pm 7.4 \mathrm{Cm}, 128.8 \pm 13.3 \mathrm{mmHg}, 84.1 \pm 10.6 \mathrm{mmHg}$, $128.9 \pm 48.9 \mathrm{mg} / \mathrm{dL}, \quad 208.2 \pm 80.7 \mathrm{mg} / \mathrm{dL}$ and $50.3 \pm 13.2 \mathrm{mg} / \mathrm{dL}$ respectively. The median hs-CRP and mean serum uric acid level was $2.5 \mathrm{mg} / \mathrm{L}(1 \mathrm{mg} / \mathrm{L}$; $5.1 \mathrm{mg} / \mathrm{L})$ and $6.6 \pm 1.8 \mathrm{mg} / \mathrm{dL}$ respectively. No significant difference in MetS components was observed among male and female patients except for waist circumference (male $106 \pm 5.4 \mathrm{Cm}$ and female $102.1 \pm 8.4 \mathrm{Cm}$; $\mathrm{p}=0.003$ ) and HDL cholesterol (male $47.2 \pm 11.9 \mathrm{mg} / \mathrm{dL}$ and female $52.7 \pm 13.6 \mathrm{mg} / \mathrm{dL}, \mathrm{p}=0.018$ ). MetS components according to level of hs-CRP and uric acid is shown in Table 1. Significant difference in MetS components; systolic BP $(\mathrm{p}=0.043)$, diastolic BP $(\mathrm{p}=0.005)$ and HDL cholesterol $(\mathrm{p}<0.001)$ was observed among patient with hs-CRP $<1 \mathrm{mg} / \mathrm{L}$ and hs-CRP $\geq 1 \mathrm{mg} / \mathrm{L}$. However, only significant difference $(\mathrm{p}=0.009)$ in MetS component; waist circumference was observed among patients with normal uric acid and hyperuricemic patients. MetS components in the 4 groups made by considering level of hs-CRP and uric acid is shown in Table 2. There was significant rise in waist circumference and diastolic BP and significant decrease in HDL cholesterol across the groups.

The correlation of hs-CRP with MetS components; waist circumference, systolic BP, diastolic BP, fasting blood glucose, triglyceride and HDL cholesterol were $0.15(\mathrm{p}=0.095),-0.008(\mathrm{p}=0.931), 0.072(\mathrm{p}=0.426)$, $0.2(\mathrm{p}=0.026), 0.124(\mathrm{p}=0.168)$ and $-0.361(\mathrm{p}<0.001)$ respectively. The correlation of serum uric acid with waist circumference, systolic BP, diastolic BP, fasting blood glucose, triglyceride and HDL cholesterol were 0.178 $(\mathrm{p}=0.047), 0.099(\mathrm{p}=0.271), 0.121(\mathrm{p}=0.181), 0.144$ $(\mathrm{p}=0.109), 0.095(\mathrm{p}=0.294)$ and $-0.034(\mathrm{p}=0.704)$. Significant correlation $(\mathrm{r}=0.19, \mathrm{p}=0.034)$ was observed between hs-CRP and serum uric acid level.

Among the study population 3, 4 and 5 components of MetS was present in 66, 37 and 22 patients respectively. All 5 components were very common in patients (19 patients out of 22) with elevated hs-CRP and hyperuricemia than compared to 4 (15 patients out of 37) and 3 (25 patients out of 66) components. Combined rise of hs-CRP and uric acid was associated with severity of MetS ( $\mathrm{p}<0.001)$. Median hs-CRP and mean uric acid level in patients with 3,4 and 5 components were $1.1 \mathrm{mg} / \mathrm{L}(1 ; 4)$ and $6.3 \pm 1.7 \mathrm{mg} / \mathrm{dL}, 3.2 \mathrm{mg} / \mathrm{L}(1.6$;

Table 1 MetS components according to hs-CRP and uric acid level

\begin{tabular}{|c|c|c|c|c|c|c|}
\hline MetS components & $\begin{array}{l}\text { Non-elevated hs- } \\
\text { CRP, } N=25\end{array}$ & $\begin{array}{l}\text { Elevated hs-CRP, } \\
\mathrm{N}=100\end{array}$ & $P$ value & $\begin{array}{l}\text { Uric acid }<6 \mathrm{mg} / \mathrm{dL} \text {, } \\
\mathrm{N}=55\end{array}$ & $\begin{array}{l}\text { Uric acid } \geq 6 \mathrm{mg} / \mathrm{dL} \\
\mathrm{N}=70\end{array}$ & $P$ value \\
\hline Waist circumference (Cm) & $101.8 \pm 6.3$ & $104.3 \pm 7.6$ & 0.14 & $101.9 \pm 6.2$ & $105.3 \pm 8$ & 0.009 \\
\hline Systolic BP (mmHg) & $124 \pm 13.2$ & $130 \pm 13.1$ & 0.043 & $127.5 \pm 14.5$ & $129.9 \pm 12.3$ & 0.318 \\
\hline Diastolic BP (mmHg) & $78.8 \pm 11.2$ & $85.5 \pm 10.1$ & 0.005 & $82.5 \pm 10.6$ & $85.4 \pm 10.5$ & 0.121 \\
\hline Fasting blood glucose (mg/dL) & $114.4 \pm 41.7$ & $132.5 \pm 50.1$ & 0.097 & $121.1 \pm 50.3$ & $135.1 \pm 47.2$ & 0.113 \\
\hline Triglyceride (mg/dL) & $188.7 \pm 55.7$ & $213.1 \pm 85.3$ & 0.087 & $210.4 \pm 89.9$ & $206.6 \pm 73.2$ & 0.795 \\
\hline HDL cholesterol (mg/dL) & $58.6 \pm 12$ & $48.2 \pm 12.6$ & $<0.001$ & $50.9 \pm 12.9$ & $49.8 \pm 13.4$ & 0.648 \\
\hline
\end{tabular}

The data is expressed as mean \pm SD

MetS metabolic syndrome, $h s-C R P$ high sensitivity $C$ reactive protein, $H D L$ high density lipoprotein 
Table 2 MetS components according to combined hs-CRP and uric acid level

\begin{tabular}{|c|c|c|c|c|c|}
\hline MetS components & $\begin{array}{l}\text { Non-elevated hs-CRP } \\
\text { and uric acid }<6 \mathrm{mg} / \mathrm{dL} \text {, } \\
\mathrm{n}=14\end{array}$ & $\begin{array}{l}\text { Non-elevated hs-CRP } \\
\text { and uric acid } \geq 6 \mathrm{mg} / \mathrm{dL} \text {, } \\
\mathrm{N}=11\end{array}$ & $\begin{array}{l}\text { Elevated hs-CRP } \\
\text { and uric acid }<6 \mathrm{mg} / \mathrm{dL} \text {, } \\
\mathrm{n}=41\end{array}$ & $\begin{array}{l}\text { Elevated hs-CRP } \\
\text { and uric acid } \geq 6 \mathrm{mg} / \mathrm{dL} \text {, } \\
\mathrm{n}=59\end{array}$ & $P$ value \\
\hline Waist circumference $(\mathrm{Cm})$ & $101.4 \pm 5.9$ & $102.4 \pm 7$ & $102 \pm 6.3$ & $105.9 \pm 8.1$ & 0.03 \\
\hline Systolic BP (mmHg) & $123.9 \pm 14.6$ & $124.1 \pm 12$ & $128.7 \pm 14.4$ & $130.9 \pm 12.2$ & 0.19 \\
\hline Diastolic BP (mmHg) & $81.4 \pm 12.2$ & $75.5 \pm 9.3$ & $82.8 \pm 10.2$ & $87.3 \pm 9.7$ & 0.002 \\
\hline $\begin{array}{l}\text { Fasting blood glucose (mg/ } \\
\mathrm{dL} \text { ) }\end{array}$ & $98.6 \pm 44.5$ & $134.5 \pm 28.4$ & $128.8 \pm 50.4$ & $135.2 \pm 50.1$ & 0.089 \\
\hline Triglyceride (mg/dL) & $198.9 \pm 53.5$ & $175.6 \pm 58.2$ & $214.3 \pm 99.6$ & $212.3 \pm 74.7$ & 0.505 \\
\hline HDL cholesterol (mg/dL) & $58.6 \pm 14.7$ & $58.7 \pm 8$ & $48.2 \pm 11.2$ & $48.1 \pm 13.6$ & 0.004 \\
\hline
\end{tabular}

The data is expressed as mean $\pm S D$

MetS metabolic syndrome, $h s-C R P$ high sensitivity $C$ reactive protein, $H D L$ high density lipoprotein

5.6) and $6.5 \pm 1.7 \mathrm{mg} / \mathrm{dL}$, and $4.4 \mathrm{mg} / \mathrm{L}(2.1 ; 8.1)$ and $7.8 \pm 1.8 \mathrm{mg} / \mathrm{dL}$ respectively. Hs-CRP $(\mathrm{p}<0.001)$ and uric acid level $(\mathrm{p}=0.005)$ were significantly different among those with 3,4 and 5 components.

Among the study patients, hypertension, hyperglycemia, hypertriglyceridemia and low HDL cholesterol were observed in $76 \%(\mathrm{n}=95), 72 \%(\mathrm{n}=90), 80 \%(\mathrm{n}=100)$ and $34.4 \%(\mathrm{n}=43)$ patients respectively. The prevalence rate of raised $\mathrm{BP}$, hyperglycemia and low HDL cholesterol was higher in group with hs-CRP $\geq 1 \mathrm{mg} / \mathrm{L}$ than $\mathrm{hs}-\mathrm{CRP}<1 \mathrm{mg} / \mathrm{L}$, and in hyperuricemia group than normal uric acid group. However, hypertriglyceridemia rate remained similar across the group. Odds ratio of having hypertension, hyperglycemia, hypertriglyceridemia and low HDL cholesterol in patients with elevated hs-CRP as compared to those with non-elevated hs-CRP, and in patients with hyperuricemia as compared to those with normal uric acid level is shown in Table 3. Significant odds of having low HDL cholesterol were observed in patients with elevated hs-CRP as compared to those with non-elevated hs-CRP. Hyperuricemic patients have significant odds of having hyperglycemia as compared to patients with normal uric acid level. The odds ratio of having hypertension, hyperglycemia, hypertriglyceridemia and low HDL cholesterol in patients with non-elevated hs-CRP and hyperuricemia, elevated hs-CRP and normal uric acid, and elevated hs-CRP and hyperuricemia as compared to the patients with non-elevated hsCRP and normal uric acid is shown in Table 3. Patients with elevated hs-CRP and normal uric acid, and with elevated hs-CRP and hyperuricemia had significant odds of having hyperglycemia as compared to those with low hs-CRP and normal uric acid.

\section{Discussion}

South Asians are more prone to develop MetS because of their high percentage of body fat, abdominal obesity, and insulin resistance (Mahalle et al. 2014). Hypertension,
MetS and diabetes mellitus has been rising in Nepalese population. Accompanying with the rise of chronic diseases like diabetes mellitus, MetS and chronic kidney diseases, there is increase in endocrine disorders like thyroid dysfunction, dyslipidemia and CVD in Nepal (Khatiwada et al. 2015a, b, 2016; Sharma et al. 2011). The present study was conducted among MetS patients in eastern Nepal. All of the study patients were obese (waist circumference $103.8 \pm 7.4 \mathrm{Cm}$ ). The mean level of MetS components was similar to our previous study among MetS patients in eastern Nepal (Khatiwada et al. 2016). Among the gender, females had significantly lower waist circumference and HDL cholesterol than male patients. Epidemiological research has shown that there is gender disparity among these components of MetS. In a study in Pakistan, similar finding among gender was reported (Jahan et al. 2007).

The median hs-CRP level $(2.5 \mathrm{mg} / \mathrm{L})$ in our study population was in risk zone and similar to the values seen in earlier studies. In a study in India, median levels of hsCRP were considerably higher in individuals with MetS (Mahajan et al. 2012). In study by Engelsen et al., median hs-CRP levels were significantly higher in individuals with central obesity with the MetS compared to individuals with central obesity without the metabolic syndrome ( 2.2 versus $1.7 \mathrm{mg} / \mathrm{L}, \mathrm{p}<0.001$ ) (den Engelsen et al. 2012). In the present study, we observed that median hsCRP level increases significantly with increasing number of MetS components. Thus, patients with all $5 \mathrm{MetS}$ components have higher hs-CRP than those with 4 and 3 components. This finding is similar to that reported by Nishida et al., who reported that individuals with an increased number of MetS components have higher CRP levels, and by Yan et al., who demonstrated increase in hs-CRP among Uyghurs and Kazakhs as the clustering of MetS components increased (Yan et al. 2015). We observed significant positive correlation between hsCRP and fasting blood glucose, and significant negative 


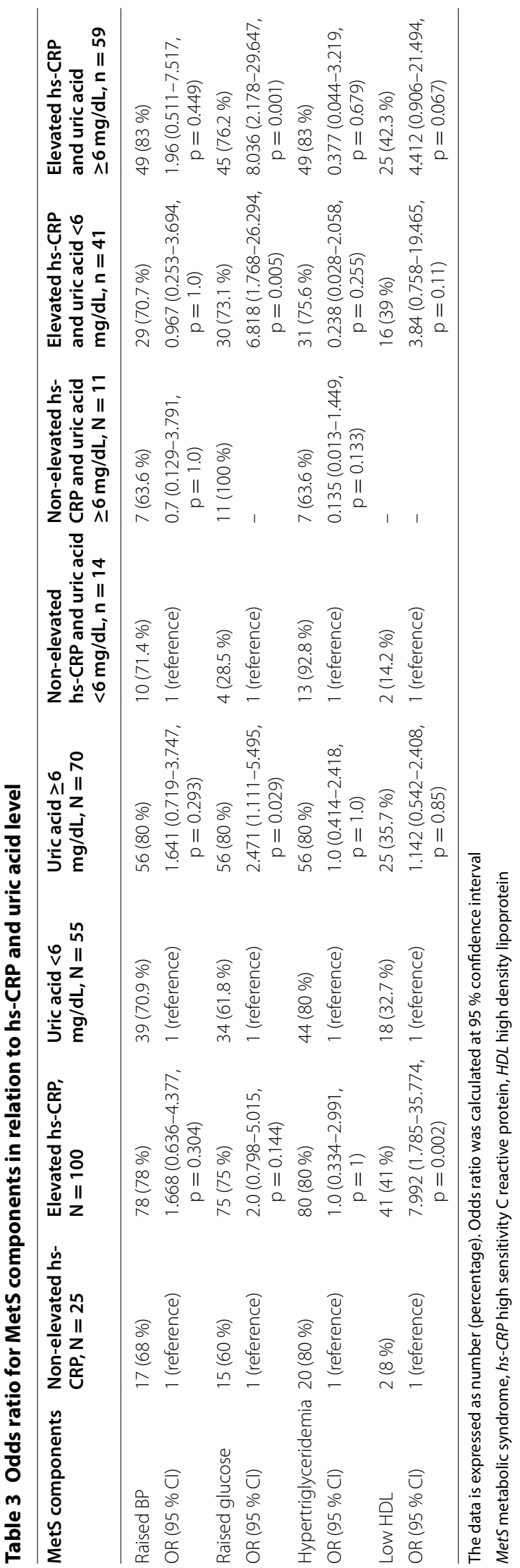


correlation of hs-CRP with HDL cholesterol. A number of studies have observed an association of hs-CRP with various MetS components (Abu-Farha et al. 2014; DeBoer et al. 2011; den Engelsen et al. 2012). In study in non-Hispanic black adolescents in US, with the exception of diastolic BP and fasting glucose, hs-CRP was significantly correlated with each of the components of MetS, however in a study among Arab population significant correlation of hs-CRP was observed with all components of MetS (Abu-Farha et al. 2014; DeBoer et al. 2011).

In our study cohort, we observed significantly higher BP (systolic and diastolic) and lower HDL cholesterol, and increasing prevalence of hypertension, hyperglycemia and low HDL cholesterol with the rise in hs-CRP. Similarly, patients with elevated hs-CRP showed higher risk for hypertension, hyperglycemia and low HDL cholesterol as compared to patients with non-elevated hs-CRP. Similar trends were observed in the study by Yan et al., where prevalence of MetS and its components increased across the quartiles of hs-CRP level, and risk for MetS and its components were higher for fourth quartile as compared to first quartile of hs-CRP (Yan et al. 2015). Another study by Kawamoto et al., also observed that prevalence rate of MetS and its components increased significantly in relation to the higher tertiles of hs-CRP, and odds ratios of hs-CRP were significantly high for obesity, hypertriglyceridemia, low HDL cholesterolemia and impaired fasting glucose (Kawamoto et al. 2013). The mechanisms by which hs-CRP reflect the risk for MetS are not completely understood. However, systemic inflammation is closely involved in the pathogenesis of MetS, and thus, elevated hs-CRP may also reflect inflammation, which impairs insulin signaling in the liver, muscle, and adipose tissues, and influence insulin resistance, lipid and glucose metabolism (Kawamoto et al. 2013). Further investigations are required to find the molecular role of CRP in the pathogenesis of MetS.

The mean serum uric acid $(6.9 \pm 1.6 \mathrm{mg} / \mathrm{dL}$ for male and $6.4 \pm 1.9 \mathrm{mg} / \mathrm{dL}$ for female) in our study population was higher than the normal range for males and females. Previous studies have also reported higher serum uric acid level in MetS patients than compared to non-MetS patients (Nejatinamini et al. 2015; Numata et al. 2008). In the current study, we found significantly higher waist circumference in patients with hyperuricemia as compared to patients with normal uric acid level and a significant positive correlation of serum uric acid with waist circumference. Study by Nejatinamini et al. (2015) and Li et al. (2011) have found strong correlation between serum uric acid and MetS components.

Our findings show that serum uric acid level increases with increase in severity of MetS, and prevalence of hypertension, hyperglycemia and low HDL cholesterol increases with the rise in serum uric acid. Also, hyperuricemic patients have higher odds of having hypertension, hyperglycemia and low HDL cholesterol as compared to patients with normal serum uric acid level. A number of previous studies have reported such findings (Lin et al. 2006; Liu et al. 2014). In the study by Lin et al., serum uric acid level was elevated significantly as the number of metabolic components increased (Lin et al. 2006). In a study in China, the prevalence of MetS increased with rise in serum uric acid and MetS component number showed an increasing trend across serum uric acid quartile in both sexes ( $\mathrm{p}$ for trend $<0.01$ ). Similarly, participants with hyperuricemia or higher serum uric acid level were at significantly elevated odd ratios for MetS and most of its five individual components (Liu et al. 2014). While it has been suggested that uric acid may simply be a consequence of the increased uric acid absorption in the proximal tubule secondary to hyperinsulinemia, there is growing data that uric acid may predict the development of MetS, obesity and diabetes. Although a strong relationship between hyperuricemia and metabolic syndrome has been established through animal and epidemiological studies, the potential pathophysiological mechanisms by which uric acid contributes to this disease state is not clear (Soltani et al. 2013).

In the present study, we reported that combined rise of hs-CRP and uric acid is associated with significant increase in level of MetS components (waist circumference and diastolic BP) and significant decrease in $\mathrm{HDL}$ cholesterol than individual rise of either hs-CRP or uric acid, and the prevalence and risk for hypertension, hyperglycemia and low HDL cholesterol is higher in patients with combined rise of hs-CRP and uric acid than in patients with either raised hs-CRP or uric acid. Also, the severity of MetS tends to be higher in patients with raised hs-CRP and raised uric acid than in patients with raised hs-CRP or uric acid, and the combined rise of hs-CRP and serum uric acid occurs more frequently in patients with higher number of MetS components. These findings are in accord to a previous study by Kawamoto et al., who found that the odds ratio of an increased tertile of uric acid and hs-CRP was a significant and independent determinant for MetS and insulin resistance. In addition to their direct associations, they also observed a synergistic effect between uric acid and hs-CRP (Kawamoto et al. 2013). Since, we observed strong association of hs-CRP with serum uric acid level in the present study, which is similar to findings of Kawamoto et al., where uric acid levels significantly increased with hs-CRP $(r=0.285$, $\mathrm{p}<0.001$ ), it may be possible that hs-CRP and uric acid act synergistically to increase severity of MetS and risk for further complications like diabetes mellitus and CVD (Kawamoto et al. 2013). Hyperuricemia has been found 
associated with elevated CRP and other inflammatory markers and there might be link between uric acid and hs-CRP (Krishnan 2014). In a study in China, hs-CRP was correlated with uric acid, and there was significant rise in prevalence of hyperuricemia with rise of hs-CRP (Sun et al. 2015).

To our knowledge, we report the association of hs-CRP and serum uric acid with MetS components for the first time in Nepalese population. Both hs-CRP and uric acid can act as an indicator of inflammation, which may negatively affect the MetS components thereby increasing CVD risk. Our previous study in eastern Nepal reported higher preponderance of CVD risk factors in subclinical hypothyroidism patients who had high hs-CRP levels than control having low hs-CRP (Kc et al. 2015). Our findings suggest that measurement of hs-CRP and uric acid may be helpful to assess severity of MetS. Because of the elevated hs-CRP in MetS patients and its ability to predict future adverse outcomes such as diabetes mellitus and CVD in MetS, adding hs-CRP as a clinical criterion for MetS may be advantageous (Devaraj et al. 2009).

The present study has some limitations, which should be considered. First, the study sample size was small, thus there might be effects on generalization of our findings. Since, this was a cross-sectional study one cannot overtly draw conclusion about the casual relationships between hs-CRP, uric acid and MetS components. Also, we did not studied hs-CRP and uric acid in subjects without any MetS components.

\section{Conclusion}

Our study finds an association of hs-CRP and serum uric acid with MetS components, though serum uric acid seems to be associated with fewer MetS components than hs-CRP. Rise of hs-CRP, uric acid, or both tends to associated with increased risk for hypertension, hyperglycemia and low HDL cholesterol. Similarly, combined rise of hs-CRP and uric acid is associated with the increase in severity of MetS. Thus, hs-CRP and uric acid may be used to assess severity of MetS.

\section{Abbreviations \\ BMI: body mass index; BP: blood pressure; CVD: cardiovascular disease; HDL: high density lipoprotein; hs-CRP: high sensitivity C reactive protein; IDF: Inter- national Diabetes Federation; LDL: low density lipoprotein; MetS: metabolic syndrome.}

\section{Authors' contributions}

SKS, SK, SP, RKC, BKLD, NB and ML designed the study. SKS, SK and RKC performed the laboratory analysis. SK performed statistical analysis and drafted the manuscript. SKS, RKC, SP, BKLD, NB and ML reviewed manuscript. All authors read and approved the final manuscript.

\section{Author details}

1 Department of Biochemistry, Universal College of Medical Sciences, Bhairahawa, Nepal. ${ }^{2}$ Department of Biochemistry, Modern Technical College,
Sanepa, Lalitpur, Nepal. ${ }^{3}$ Department of Biochemistry, B P Koirala Institute of Health Sciences, Dharan, Nepal.

\section{Acknowledgements}

We would like to acknowledge University Grants Commission for their financial support and B P Koirala Institute of Health Sciences for providing resources to conduct the study.

\section{Competing interests}

The authors declare that they have no competing interests.

Received: 11 January 2016 Accepted: 24 February 2016

Published online: 03 March 2016

\section{References}

Abu-Farha M, Behbehani K, Elkum N (2014) Comprehensive analysis of circulating adipokines and hsCRP association with cardiovascular disease risk factors and metabolic syndrome in Arabs. Cardiovasc Diabetol 13:76

Billiet L, Doaty S, Katz JD, Velasquez MT (2014) Review of hyperuricemia as new marker for metabolic syndrome. ISRN Rheumatol 2014:852954

DeBoer MD, Gurka MJ, Sumner AE (2011) Diagnosis of the metabolic syndrome is associated with disproportionately high levels of high-sensitivity C-reactive protein in non-Hispanic black adolescents: an analysis of NHANES 1999-2008. Diabetes Care 34(3):734-740

den Engelsen C, Koekkoek PS, Gorter KJ, van den Donk M, Salomé PL, Rutten GE (2012) High-sensitivity C-reactive protein to detect metabolic syndrome in a centrally obese population: a cross-sectional analysis. Cardiovasc Diabetol 11:25

Devaraj S, Singh U, Jialal I (2009) Human C-reactive protein and the metabolic syndrome. Curr Opin Lipidol 20(3):182-189

Jahan F, Qureshi R, Borhany T, Hamza HB (2007) Metabolic syndrome: frequency and gender differences at an out-patient clinic. J Coll Physicians Surg Pak 17(1):32-35

Kaur J (2014) A comprehensive review on metabolic syndrome. Cardiol Res Pract 2014:943162

Kawamoto R, Tabara Y, Kohara K, Miki T, Kusunoki T, Takayama S, Abe M, Katoh T, Ohtsuka N (2013) Usefulness of combining serum uric acid and high-sensitivity C-reactive protein for risk stratification of patients with metabolic syndrome in community-dwelling women. Endocrine 44(1):132-139

Kc R, Khatiwada S, Deo Mehta K, Pandey P, Lamsal M, Majhi S (2015) Cardiovascular risk factors in subclinical hypothyroidism: a case control study in Nepalese population. J Thyroid Res 2015:305241. doi:10.1155/2015/305241

Khatiwada S, Kc R, Gautam S, Lamsal M, Baral N (2015a) Thyroid dysfunction and dyslipidemia in chronic kidney disease patients. BMC Endocr Disord 15:65. doi:10.1186/s12902-015-0063-9

Khatiwada S, Kc R, Sah SK, Khan SA, Chaudhari RK, Baral N, Lamsal M (2015b) Thyroid dysfunction and associated risk factors among Nepalese diabetes mellitus patients. Int J Endocrinol 2015:570198. doi:10.1155/2015/570198

Khatiwada S, Sah SK, Kc R, Baral N, Lamsal M (2016) Thyroid dysfunction in metabolic syndrome patients and its relationship with components of metabolic syndrome. Clin Diabetes Endocrinol 2:3. doi:10.1186/ s40842-016-0021-0

Krishnan E (2014) Interaction of inflammation, hyperuricemia, and the prevalence of hypertension among adults free of metabolic syndrome: NHANES 2009-2010. J Am Heart Assoc 3(2):e000157

Li Q, Yang Z, Lu B, Wen J, Ye Z, Chen L, He M, Tao X, Zhang W, Huang Y et al (2011) Serum uric acid level and its association with metabolic syndrome and carotid atherosclerosis in patients with type 2 diabetes. Cardiovasc Diabetol 10:72

Lin SD, Tsai DH, Hsu SR (2006) Association between serum uric acid level and components of the metabolic syndrome. J Chin Med Assoc 69(11):512-516

Liu M, He Y, Jiang B, Wu L, Yang S, Wang Y, Li X (2014) Association between serum uric acid level and metabolic syndrome and its sex difference in a Chinese community elderly population. Int J Endocrinol 2014:754678 
Ma K, Jin X, Liang X, Zhao Q, Zhang X (2012) Inflammatory mediators involved in the progression of the metabolic syndrome. Diabetes Metab Res Rev 28:388-394

Mahajan A, Jaiswal A, Tabassum R, Podder A, Ghosh S, Madhu SV, Mathur SK, Tandon N, Bharadwaj D (2012) Elevated levels of C-reactive protein as a risk factor for metabolic syndrome in Indians. Atherosclerosis 220(1):275-281

Mahalle N, Garg MK, Naik SS, Kulkarni MV (2014) Association of metabolic syndrome with severity of coronary artery disease. Indian J Endocrinol Metab 18(5):708-714

Nejatinamini S, Ataie-Jafari A, Qorbani M, Nikoohemat S, Kelishadi R, Asayesh $\mathrm{H}$, Hosseini S (2015) Association between serum uric acid level and metabolic syndrome components. J Diabetes Metab Disord 14:70

Numata T, Miyatake N, Wada J, Makino H (2008) Comparison of serum uric acid levels between Japanese with and without metabolic syndrome. Diabetes Res Clin Pract 80(1):e1-e5

O'Neill S, O'Driscoll L (2015) Metabolic syndrome: a closer look at the growing epidemic and its associated pathologies. Obes Rev 16(1):1-12

Paoletti R, Bolego C, Poli A, Cignarella A (2006) Metabolic syndrome, inflammation and atherosclerosis. Vasc Health Risk Manag 2(2):145-152
Serpa Neto A, Rossi FM, Valle LG, Teixeira GK, Rossi M (2011) Relation of uric acid with components of metabolic syndrome before and after Roux-enY gastric bypass in morbidly obese subjects. Arq Bras Endocrinol Metabol 55(1):38-45

Sharma SK, Ghimire A, Radhakrishnan J, Thapa L, Shrestha NR, Paudel N, Gurung K, Budathoki A, Baral N et al (2011) Prevalence of hypertension, obesity, diabetes, and metabolic syndrome in Nepal. Int J Hypertens 2011:821971

Soltani Z, Rasheed K, Kapusta DR, Reisin E (2013) Potential role of uric acid in metabolic syndrome, hypertension, kidney injury, and cardiovascular diseases: is it time for reappraisal? Curr Hypertens Rep 15(3):175-181

Sun M, Zhang L, Chen S, Liu X, Shao X, Zou H (2015) Association of C-reactive protein and metabolic disorder in a Chinese population. Int J Environ Res Public Health 12(7):8228-8242

Yan YZ, Ma RL, Ding YS, Guo H, Zhang JY, Mu LT, Zhang M, Liu JM, Rui DS, He J et al (2015) Association of inflammation with metabolic syndrome among low-income rural Kazakh and Uyghur adults in far western China. Mediators Inflamm 2015:706768

\section{Submit your manuscript to a SpringerOpen ${ }^{\odot}$ journal and benefit from:}

- Convenient online submission

- Rigorous peer review

- Immediate publication on acceptance

- Open access: articles freely available online

- High visibility within the field

- Retaining the copyright to your article

Submit your next manuscript at $\boldsymbol{s p r i n g e r o p e n . c o m ~}$ 